\title{
Exploring the relationship between depression and different multimorbidity patterns among older people covered by long-term care insurance in Shanghai, China
}

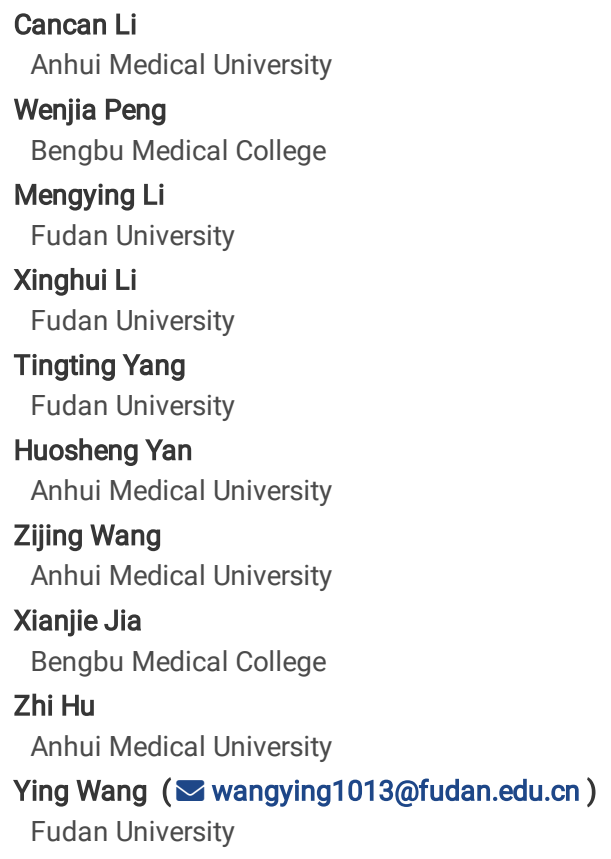

Version of Record: A version of this preprint was published at Psychogeriatrics on November 7th, 2021. See the published version at https://doi.org/10.1111/psyg.12783. 


\section{Abstract}

Background: Depression is common in patients with multimorbidity, but little is known about the relationship between depression and multimorbidity. The purpose of our research was to investigate multimorbidity patterns and their association with depression in a sample of older people covered by long-term care insurance in Shanghai, China.

Method: This was a population-based cross-sectional study, and participants included older people covered by long-term care insurance in Shanghai. We collected information on chronic conditions using a self-reported medical history, and we used the 30-item Geriatric Depression Scale to evaluate depressive symptoms. Patterns of multimorbidity were identified with exploratory factor analysis, using oblimin rotation. Logistic regression was used to estimate the relationship between multimorbidity patterns and depressive symptoms.

Results: Hypertension, cardiovascular disease, cerebrovascular disease (CVD), and cataract showed strong associations with depression when co-occurring with other conditions. Three patterns of multimorbidity were identified: a musculoskeletal pattern, cardiometabolic pattern, and degenerative disease pattern. Among these, the cardiometabolic (adjusted odds ratio [AOR] 1.223; 95\% confidence interval [CI] 1.102, 1.357) and degenerative disease (AOR 1.185; $95 \% \mathrm{Cl}$ $1.071,1.311)$ patterns were associated with a higher risk of depressive symptoms.

Conclusion: Two of three multimorbidity patterns were found to be associated with depression. Physical and psychological dimensions require greater attention in the care of older adults who are covered by long-term care insurance.

\section{Background}

Depression is a major global health problem with a lifetime prevalence ranging from 1.5-19\%(1). It is one of the main diseases causing disease burden and the third leading cause of years lived with disability globally(2). Multimorbidity is generally defined as the co-occurrence of two or more chronic diseases(3). Accelerated aging of the global population has largely contributed to the increased prevalence of multimorbidity(4).Among people over 50 years old in European countries, the prevalence of multimorbidity is 37\%(5). A study of the prevalence of multimorbidity in Australia found that $75 \%$ of those aged $65-74$ years had multimorbidity, and this proportion rose to $80 \%$ among people 75 years and older(6). Additionally, the prevalence of multimorbidity ranges from $24.1-83 \%$ among the population over 60 years old in South Asia(7) and from 6.4-76.5\% among the population over 60 years old in China(8).

A large number of studies have proved that multimorbidity is associated with various poor health outcomes, such as poor health-related quality of life (HRQL) (9) and higher health care expenditures and resource utilization $(5,10)$. Compared with patients who have a single disease, management of the medical needs of patients with multimorbidity increases complexity and a series of impacts on social and emotional functions should be considered(11).

In the context of global aging, people have begun to pay greater attention to the relationship between multimorbidity and depression. Previous research has documented that people with one or more chronic physical diseases have a higher proportion of depression than those with no chronic illness(12). Several meta-analyses have found that the risk of depression is twice as high among people with multimorbidity than in those without multimorbidity and three times greater for people with multimorbidity than those without any chronic physical conditions(13). In further research, it was found that quality of life in patients with both multiple diseases and depression was significantly lower than in those with chronic diseases but who were not depressed(12). Multimorbidity together with depression is a huge public health challenge for low- and middle-income countries with limited health resources(14).

China's older population is expected to reach 400 million by 2050(15). To be able to address problems caused by a large aging population, China began to explore a long-term care insurance system in 2016(16). Previous research shows that older people with chronic diseases are at higher risk of depression(17, 18), especially those living in long-term care facilities(3). Better understanding and greater attention paid to the relationship between multimorbidity and depression are needed, to promote more targeted measures for reducing the burden of disease and to improve the health of the population(12). Therefore, research on the relationship between multimorbidity and depression is critically important. For China, such research will help improve its long-term care insurance system, to help promote a healthy aging population. However, there is little research in this area and related studies have mostly been carried out in Western countries. In the Chinese older population, some studies on chronic diseases and depression have emerged in recent years, but most of these have focused on the relationship between a single disease or the number of diseases and depression. Few studies have examined the relationship between multimorbidity patterns and depression. Moreover, there is nearly no research among participants in long-term care insurance. The purpose of this study was to explore multimorbidity patterns among people covered by long-term care insurance in Shanghai and the relationship with depression. The selected data were obtained from a population of older people in a study of the Shanghai long-term care insurance system.

\section{Methods}

\subsection{Study Population and Data Collection}

This was a population-based cross-sectional study conducted among participants in a study of older people covered by long-term care insurance in Shanghai, China. Our study adopted stratified cluster sampling. The city of Shanghai was divided into 17 districts in 2015, and further divided into levels according to the city center, suburbs, and outer suburbs. Random sampling was carried out at each level; three, two, and one sample districts were selected from the city center, suburbs, and outer suburbs, respectively. In the six sample districts selected, one street was selected as the survey street, based on the Chinese character stroke order of the street name.

We randomly selected one to three neighborhood committees from the corresponding survey streets, randomly selected according to their age composition. 
We excluded individuals with severe cognitive impairment and those who were unable to participate owing to hearing, language, or mental impairment. Finally, a total of 1,871 older individuals were included in the present study. This research mainly used survey questionnaires to collect information. The questionnaires were completed by specially trained investigators in face-to-face interviews.

This study was approved by the Fudan University Research Ethics Committee and performed in accordance with the current institutional and state guidelines and regulations.

Written informed consent was obtained from all participants.

\subsection{Sociodemographic and Health-Related Variables}

Social demographic variables include sex, age (60-69, 70-79, 80-89 and $\geq 90$ years), education level (illiterate, primary school, middle school or technical school, college or above), marital status (divorced, widowed, never married, or married), children (with or without), monthly income in Chinese yuan ( $<1800$, 1800-3499, 3500-3999 and $\geq 4000$ )(19), and care mode (home or facility).

In this study, we also used the Perceived Social Support Scale (PSSS) to investigate social support among participants. PSSS is a validated 12-item instrument used to evaluate perceived support from three groups, namely, family, friends, and significant others. The PSSS score ranges from 12 to 84 ; the higher the score, the higher the perceived level of social support. The Chinese version of the PSSS has been verified and has good internal reliability. In this study, social support was divided into three categories, the first category comprised scores of 12-31 points, the second category was 32-50 points, and the third category was 51-84 points(20-22).

\subsection{Definition of Chronic Conditions and Multimorbidity}

Chronic diseases are measured based on participants' answers to the following question: "Have you had a chronic disease diagnosed by a doctor in the past 6 months?" This referred to 33 chronic diseases, including hypertension, diabetes, cardiovascular disease (heart attack and other cardiovascular disorders), cerebrovascular disease (CVD), bronchitis, pneumonia, emphysema, asthma or chronic obstructive pulmonary disease, tuberculosis, cataract, glaucoma, cancer, prostatitis/prostatic hypertrophy, Parkinson disease, bedsores, injury or poisoning, rheumatoid arthritis, intervertebral disc disease, chronic low back pain, dyslipidemia, severe vision loss, psychiatric disease, lower extremity varicose veins, gout, hemorrhoids, hypothyroidism, non-inflammatory gynecological diseases, psoriasis, osteoporosis, chronic cholecystitis/gallstones, urinary stones, and anemia. Multimorbidity was defined as having two or more of the 33 chronic diseases at the same time.

\subsection{Assessments of Depression}

To assess depression, we used the 30-item Geriatric Depression Scale (GDS-30), which contains 30 questions. Respondents answer "yes" or "no" based on how they have felt in the past week(23). Among the questions, 20 questions receive 1 point for a response of "yes" and 0 points for "no". The other 10 questions are reverse scored; the full score is 30 , and an individual score $\geq 11$ is considered to indicate depressive symptoms. The GDS-30 is widely used as an effective screening tool for depressive symptoms in older people $(24,25)$, and it is also applicable to people over age 60 years in China(26, 27).

\subsection{Statistical Analyses}

Descriptive analysis was used to describe the demographic characteristics of participants. The chi-square test was used for categorical variables. Exploratory factor analysis is often used to identify multimorbidity patterns $(28,29)$. We applied the principal factor method based on a tetrachoric correlation matrix. The Kaiser-Meyer-Olkin method and Bartlett test of sphericity were performed to estimate adequacy of the data for our model. Eigenvalues greater than 1 and a scree plot were used to determine the number of retained factors(30). A condition with factor loading $\geq 0.40$ was regarded as having a strong association(31), and one condition was assigned to the pattern with larger factor loading if its factor loadings were $>0.40$ in more than one pattern when labeling patterns. To improve robustness, we excluded conditions with a prevalence $<5.0 \%(28)$.

Binary logistic regression was used to estimate the relationship between multimorbidity patterns and depressive symptoms, and to adjust for sociodemographic variables. We used IBM SPSS version 25.0 for all data analyses (IBM Corp., Armonk, NY, USA).

\section{Results}

\subsection{General Characteristics of Participants}

Tables 1 and 2 show the characteristics of participants with respect to depression and multimorbidity. Among the 1871 participants, 1,142 (61\%) were women; most participants were 80-89 years old, accounting for 53.9\%. Overall, the study population reported having a good degree of social support. Among all participants, $64.6 \%$ were considered to have depressive symptoms; those with depressive symptoms were more likely to be receiving home-based care and to have a primary school education and low social support scores. Differences with respect to sex, marital status, and age between participants with and without depressive symptoms was not significant. Multimorbidity was present in $64.7 \%$ of participants. Compared with people with no chronic physical conditions, those multimorbidity mainly lived at home and had higher social support scores. 
Table 1

Characteristics of the Study Participants According to Depression.

\begin{tabular}{|c|c|c|c|c|c|}
\hline Characteristic & $N(\%)$ & $\begin{array}{l}\text { No depression, } \\
\text { (\%) }\end{array}$ & Depression, (\%) & $x^{2}$ & P-value \\
\hline Total & 1871(100.0) & $662(35.4)$ & $1209(64.6)$ & & \\
\hline Care mode & & & & 10.093 & 0.001 \\
\hline Home & $1067(57.0)$ & $345(32.3)$ & $722(67.7)$ & & \\
\hline Facility & $804(43.0)$ & $317(39.4)$ & $487(60.6)$ & & \\
\hline Sex & & & & 0.619 & 0.431 \\
\hline Male & $729(39.0)$ & $250(34.3)$ & $479(65.7)$ & & \\
\hline Female & $1142(61.0)$ & $412(36.1)$ & $730(63.9)$ & & \\
\hline Age,years & & & & 4.997 & 0.172 \\
\hline $60-69$ & 123(6.6) & $36(29.3)$ & 87(70.7) & & \\
\hline $70-79$ & $345(18.4)$ & 116(33.6) & $229(66.4)$ & & \\
\hline $80-89$ & $1009(53.9)$ & $378(37.5)$ & $631(62.5)$ & & \\
\hline$\geq 90$ & $394(21.1)$ & 132(33.5) & $262(66.5)$ & & \\
\hline Education levels & & & & 16.712 & 0.001 \\
\hline Illiteracy & $656(35.0)$ & $243(37.0)$ & $413(63.0)$ & & \\
\hline primary school & $473(25.3)$ & $140(29.6)$ & $333(70.4)$ & & \\
\hline Middle school or technical school & $574(30.7)$ & 201(35.0) & $373(65.0)$ & & \\
\hline Junior college or above & 168(9.0) & $78(46.4)$ & $90(53.6)$ & & \\
\hline Marital status & & & & 1.350 & 0.245 \\
\hline Divorced, widowed, never married & $1080(57.7)$ & $394(36.5)$ & $686(63.5)$ & & \\
\hline Married & $791(42.3)$ & $268(33.9)$ & $583(66.1)$ & & \\
\hline Children & & & & 1.834 & 0.176 \\
\hline No & $78(4.2)$ & $22(28.2)$ & $56(71.8)$ & & \\
\hline Yes & 1793(95.8) & $640(35.7)$ & 1153(64.3) & & \\
\hline Income, $\mathrm{CNY}^{\dagger}$ & & & & 14.012 & 0.003 \\
\hline Q1800 & $460(24.6)$ & 177(38.5) & $283(61.5)$ & & \\
\hline $1800-3499$ & $375(20.0)$ & $121(32.3)$ & $254(67.7)$ & & \\
\hline $3500-3999$ & $239(12.8)$ & $63(26.4)$ & 176(73.6) & & \\
\hline$\geq 4000$ & $797(42.6)$ & $301(37.8)$ & $496(62.2)$ & & \\
\hline Social support & & & & 101.347 & 0.000 \\
\hline $12-31$ & $58(3.1)$ & $12(20.7)$ & $46(79.3)$ & & \\
\hline $32-50$ & $706(27.7)$ & $156(22.1)$ & $550(77.9)$ & & \\
\hline $51-84$ & 1107(59.2) & 494(35.4) & 613(55.4) & & \\
\hline
\end{tabular}


Table 2

Characteristics of Study Participants According to Multimorbidity.

\begin{tabular}{|c|c|c|c|c|c|}
\hline Characteristic & $N(\%)$ & Without multimorbidity(\%) & Multimorbidity(\%) & $x^{2}$ & P-value \\
\hline Total & 1871(100.0) & $660(35.3)$ & $1211(64.7)$ & & \\
\hline Care mode & & & & 5.255 & 0.022 \\
\hline Home & $1067(57.0)$ & $353(33.1)$ & $714(66.9)$ & & \\
\hline Facility & $804(43.0)$ & $307(38.2)$ & $497(61.8)$ & & \\
\hline Sex & & & & 1.157 & 0.282 \\
\hline Male & $729(39.0)$ & $268(36.8)$ & $461(63.2)$ & & \\
\hline Female & $1142(61.0)$ & $392(34.3)$ & $750(65.7)$ & & \\
\hline Age, years & & & & 7.821 & 0.050 \\
\hline $60-69$ & $123(6.6)$ & $47(38.2)$ & $76(61.8)$ & & \\
\hline $70-79$ & $345(18.4)$ & $106(30.7)$ & $239(69.3)$ & & \\
\hline $80-89$ & $1009(53.9)$ & $349(34.6)$ & $660(65.4)$ & & \\
\hline$\geq 90$ & $394(21.1)$ & $158(40.1)$ & $236(59.9)$ & & \\
\hline Education levels & & & & 0.718 & 0.869 \\
\hline Illiteracy & $656(35.0)$ & $235(35.8)$ & $421(64.2)$ & & \\
\hline Primary school & $473(25.3)$ & $160(33.8)$ & $313(66.2)$ & & \\
\hline Middle school or technical school & $574(30.7)$ & 203(35.4) & $371(64.6)$ & & \\
\hline Junior college or above & $168(9.0)$ & $62(36.9)$ & $106(64.1)$ & & \\
\hline Marital status & & & & 1.624 & 0.204 \\
\hline Divorced, widowed, never married & $1080(57.7)$ & $368(34.1)$ & $712(65.9)$ & & \\
\hline Married & $791(42.3)$ & 292(36.9) & $499(63.1)$ & & \\
\hline Children & & & & 3.283 & 0.070 \\
\hline No & $78(4.2)$ & $35(44.9)$ & $43(55.1)$ & & \\
\hline Yes & 1793(95.8) & $625(34.9)$ & $1168(65.1)$ & & \\
\hline Income, ${ }^{\dagger} \mathrm{CNY}$ & & & & 4.603 & .203 \\
\hline$\nabla 1800$ & $460(24.6)$ & 176(38.3) & $284(61.7)$ & & \\
\hline $1800-3499$ & $375(20.0)$ & 133(35.5) & $242(64.5)$ & & \\
\hline $3500-3999$ & $239(12.8)$ & 72(30.1) & 167(69.9) & & \\
\hline$\geq 4000$ & $797(42.6)$ & $279(35.0)$ & $518(65.0)$ & & \\
\hline Social support & & & & 12.487 & 0.002 \\
\hline $12-31$ & $58(3.1)$ & $25(43.1)$ & $33(56.9)$ & & \\
\hline $32-50$ & 706(37.7) & $280(39.7)$ & $426(60.3)$ & & \\
\hline $51-84$ & 1107(59.2) & $355(32.1)$ & $752(67.9)$ & & \\
\hline
\end{tabular}

\subsection{Chronic Diseases and Depression}

Of the 33 somatic conditions included in our study, 10 with a prevalence of $>5 \%$ were included in the analysis. Table 3 (end of the document text file) shows the prevalence of chronic disease, depression under different conditions, and the relationship between chronic diseases and depression. Hypertension showed the highest prevalence in this population. Further, only hypertension had an association with the presence of depressive symptoms when occurring without multimorbidity. Most conditions were significantly associated with depression when co-occurring with other conditions, after adjusting for all potential confounding factors. 
Table 3

Associations Between Chronic Diseases and Depression ( $\mathrm{N}=1871)$.

\begin{tabular}{|c|c|c|c|c|c|c|c|}
\hline \multirow{2}{*}{$\begin{array}{l}\text { Chronic } \\
\text { Diseases }\end{array}$} & \multicolumn{2}{|l|}{ Prevalence, n(\%) } & \multicolumn{2}{|c|}{ Depression Prevalence, $n(\%)$} & \multicolumn{3}{|c|}{ Adjusted $^{\dagger} \mathrm{OR}^{\S}(95 \% \mathrm{Cl})$} \\
\hline & $\begin{array}{l}\text { Without } \\
\text { Multimorbidity }\end{array}$ & $\begin{array}{l}\text { With } \\
\text { Multimorbidity }\end{array}$ & $\begin{array}{l}\text { Without } \\
\text { Multimorbidity }\end{array}$ & $\begin{array}{l}\text { With } \\
\text { Multimorbidity }\end{array}$ & $\begin{array}{l}\text { No } \\
\text { Condition }\end{array}$ & $\begin{array}{l}\text { Without } \\
\text { Multimorbidity }\end{array}$ & $\begin{array}{l}\text { With } \\
\text { Multimorbidity }\end{array}$ \\
\hline Hypertension & 106(16.1) & $911(75.2)$ & $57(3.0)$ & 614(32.8) & Reference & $0.601(0.377,0.957)$ & $1.516(1.132,2.030)$ \\
\hline Diabetes & $16(2.4)$ & $396(32.7)$ & $7(0.3)$ & $275(14.7)$ & & $0.513(0.180,1.461)$ & $1.274(0.965,1.682)$ \\
\hline $\begin{array}{l}\text { Cardiovascular } \\
\text { disease }\end{array}$ & $49(7.4)$ & $605(50.0)$ & $34(1.8)$ & $420(22.4)$ & & $1.178(0.600,2.311)$ & $1.467(1.135,1.897)$ \\
\hline CVD & 26(3.9) & 237(19.6) & $20(1.1)$ & $170(9.1)$ & & $1.678(0.627,4.493)$ & $1.666(1.191,2.331)$ \\
\hline Cataract & $6(0.9)$ & $151(12.5)$ & $4(0.2)$ & $79(4.2)$ & & $1.167(0.186,7.311)$ & $0.451(0.307,0.662)$ \\
\hline $\begin{array}{l}\text { Severe vision } \\
\text { loss }\end{array}$ & $0(0.0)$ & $105(8.7)$ & $0(0,0)$ & $63(3.4)$ & & - $\neq$ & $0.902(0.564,1.442)$ \\
\hline $\begin{array}{l}\text { Rheumatoid } \\
\text { arthritis }\end{array}$ & $6(0.9)$ & $151(12.5)$ & $0(0,0)$ & $118(6.3)$ & & - & $0.935(0.659,1.326)$ \\
\hline $\begin{array}{l}\text { Intervertebral } \\
\text { disc Disease }\end{array}$ & $3(0.5)$ & $114(9.4)$ & $2(0.1)$ & $76(4.1)$ & & $1.772(0.143,21.962)$ & $1.486(0.909,2.426)$ \\
\hline $\begin{array}{l}\text { Chronic low } \\
\text { back pain }\end{array}$ & $0(0.0)$ & 134(11.1) & $0(0,0)$ & $78(4.2)$ & & - & $0.708(0.455,1.102)$ \\
\hline Osteoporosis & $7(1.1)$ & $164(13.5)$ & $4(0.2)$ & $96(5.1)$ & & $0.680(0.138,3.338)$ & $0.912(0.623,1.333)$ \\
\hline \multicolumn{8}{|c|}{$\begin{array}{l}\text { † Participants without the condition were regarded as the reference group in all models. All patterns were adjusted for care mode, age, sex, marital status, } \\
\text { education level, personal income, children, and social support. Boldface indicates statistical significance }(P<.05) \text {. }\end{array}$} \\
\hline \multicolumn{8}{|c|}{ ₹ There were no patients with depression among participants with no multimorbidity. } \\
\hline \multicolumn{8}{|l|}{$\S$ Odds Ratio. } \\
\hline Ce & isease & & & & & & \\
\hline
\end{tabular}

\subsection{Patterns of Chronic Multimorbidity}

Among the 10 diseases analyzed, we identified three patterns of chronic multimorbidity, which could explain $45.1 \%$ of the total variance(Table 4$)$ : a musculoskeletal pattern (including rheumatoid arthritis, intervertebral disc disease, and chronic low back pain), cardiometabolic pattern (including hypertension, diabetes, cardiovascular diseases, and CVD), and degenerative diseases pattern (including cataract, severe vision loss, and osteoporosis) 
Table 4

Factor Loadings of the Three Multimorbidity Patterns for Each Disease

\begin{tabular}{|c|c|c|c|}
\hline \multirow{2}{*}{$\begin{array}{l}\text { Chronic Diseases } \\
\text { and Parameters }\end{array}$} & \multicolumn{3}{|l|}{ Factor $^{\dagger}$} \\
\hline & Factor1 & Factor2 & Factor3 \\
\hline Rheumatoid arthritis & 0.52 & 0.25 & 0.16 \\
\hline Intervertebral disc disease & 0.78 & 0.09 & -0.07 \\
\hline Chronic low back pain & 0.76 & 0.06 & -0.15 \\
\hline Hypertension & 0.01 & 0.71 & -0.11 \\
\hline Diabetes & -0.07 & 0.62 & -0.04 \\
\hline Cardiovascular disease & -0.01 & 0.55 & -0.22 \\
\hline CVD & 0.14 & 0.45 & 0.26 \\
\hline Cataract & -0.09 & 0.18 & -0.65 \\
\hline Severe vision loss & 0.08 & 0.07 & -0.69 \\
\hline Osteoporosis & 0.32 & 0.08 & -0.52 \\
\hline Eigenvalue & 2.12 & 1.33 & 1.06 \\
\hline Cumulative percentage & $21.2 \%$ & $34.5 \%$ & $45.1 \%$ \\
\hline \multicolumn{4}{|c|}{$\begin{array}{l}{ }^{\dagger} \text { Factor loadings indicate the strength of association between each variable and each factor, with a factor loading of } \geq 0.4 \text { considered to be strong in this } \\
\text { study (indicated in bold). }\end{array}$} \\
\hline
\end{tabular}

\subsection{Different Multimorbidity Patterns and Depression}

Table 5 shows the results of binary logistic regression between multimorbidity patterns and depression. After adjusting for potential confounding variables, the increase in factor scores in cardiometabolic and degenerative disease patterns was associated with a high risk of depressive symptoms.

Table 5

Associations Between Multimorbidity Patterns with the Presence of Depressive Symptoms ( $N=1871)$.

\begin{tabular}{|c|c|c|c|c|}
\hline \multirow[t]{2}{*}{ Multimorbidity Patterns } & \multicolumn{2}{|c|}{ Unadjusted } & \multicolumn{2}{|c|}{ Adjusted $^{\dagger}$} \\
\hline & $\mathrm{OR}^{\ddagger}$ & $95 \% \mathrm{Cl} \S$ & OR & $95 \% \mathrm{Cl}$ \\
\hline Musculoskeletal & 0.964 & 0.8761 .061 & 0.992 & $0.896-1.099$ \\
\hline Cardiometabolic & 1.190 & $1.079-1.313$ & 1.223 & $1.102-1.357$ \\
\hline Degenerative diseases & 1.157 & $1.053-1.272$ & 1.185 & $1.071-1.311$ \\
\hline \multicolumn{5}{|c|}{$\begin{array}{l}{ }^{\dagger} \text { All patterns were adjusted for care mode, age, sex, marital status, education level, personal income, children, and social support. Boldface indicate } \\
\text { statistical significance }(P<.05) \text {. }\end{array}$} \\
\hline
\end{tabular}

\section{Discussion}

In this study, the prevalence of both multimorbidity and depression was high and social support was associated with multimorbidity and depression. Hypertension, cardiovascular disease, CVD, and cataract had strong associations with depression when they co-occurred with other conditions. Compared with having a single disease, there were more diseases associated with depression in a multimorbid state. In addition, three patterns of multimorbidity were identified: a musculoskeletal pattern, cardiometabolic pattern, and degenerative disease pattern. Among these, the cardiometabolic and degenerative disease patterns were associated with a higher risk of the presence of depressive symptoms.

The prevalence of multimorbidity in this study was $64.7 \%$, which is in line with the findings of Hu that older people in Chinese communities have rates of multimorbidity between $6.4 \%$ and $76.5 \%(8)$; however, our results were higher than the $41.56 \%$ found in communities of eastern China(32). Depression is known to be the most common psychological disorder among older adults. In the United States, approximately $15-20 \%$ of older adults experience depression each year(33). Studies that have investigated the prevalence of depression among older people in mainland China have reported depression rates ranging from $15.8-30.8 \%(34-36)$, probably owing to the use of different methodologies. The prevalence of depression was $64.6 \%$. This may be because our participants were covered by long-term care insurance and had poor physical conditions, with most over age 80 years. Their physical functions were greatly reduced, but multimorbidity may share common pathologic pathways with mental disorders $(37,38)$. The impact of social support on multimorbidity and depression has 
been reported. Social support is negatively related to depression $(39,40)$. In our research as well, social support scores were lower for people with multimorbidity and depression. Impaired social support and feelings of loneliness are considered to be risk factors for depression in older people(41, 42). When we performed regression analysis, social support was included as an adjustment variable, taking full account of the impact of social support on multimorbidity and depression.

Previous studies concerning the associations between chronic disease and depression have mostly focused on a single condition or the number of comorbid conditions. A large volume of literature has demonstrated that depression is associated with several somatic conditions such as hypertension, heart diseases, and stroke(43-45), which was also observed in our study. Indeed, the simultaneous presentation of diseases in one individual may have a multiplicative, rather than additive, effect on the individual's health(46). Thus, compared with those who have no chronic diseases or without multimorbidity, people with multimorbidity are indeed more prone to depressive symptoms.

The multimorbidity patterns in this study were similar to those observed previously, and common antecedents and disease pathways may explain these patterns. A systematic review found three major multimorbidity patterns among older adults living in Western countries, which are cardiovascular-metabolic, mental health, and musculoskeletal disorders(28). In China, a cohort study also identified four multimorbidity patterns: a cardiometabolic pattern, respiratory pattern, arthritic-digestive-visual pattern, and hepatic-renal-skeletal pattern(31). In our research, the musculoskeletal model includes chronic low back pain, rheumatoid arthritis, and intervertebral disc disease. Previous studies have also found the existence of this model, and all of them included at least one musculoskeletal disease(28). Musculoskeletal patterns or arthritis included in these patterns are often associated with the occurrence of depressive symptoms(47-49). In this study, there may be no correlation between the two owing to the low prevalence of related diseases; however, this warrants further investigation. The cardiometabolic pattern is the most widely described pattern in previous studies. The diseases included in this model differ in each study, but the core diseases are the same, such as heart disease, hypertension, diabetes, and others $(28,50)$. Moreover, the relationship between this model and depression has also been confirmed in many studies(13). Among the three multimorbidity patterns found, the cardiometabolic pattern had the strongest association with depression, which is consistent with previous studies. Degenerative diseases include cataract, severe vision loss, and osteoporosis. In previous studies, multimorbidity patterns including joint and eye diseases have been found $(9,31,51,52)$. Such multimorbidity patterns are not scarce in such studies; previous evidence supports an association between conditions in this pattern through factors such as inflammation, side effects of medications, and so on $(53,54)$. The strong correlation between bone diseases and eye diseases may permit the discovery of potential links. The differences in multimorbidity patterns across studies might be partly attributable to remarkable heterogeneity in the number, type, and assessment approach of chronic conditions as well as in characteristics of the study samples. However, common components have been identified.

In estimation of the three multimorbidity patterns and depression, two were found to be associated with depression, namely, the cardiometabolic and degenerative disease patterns. In addition, strong correlations were found between cardiovascular diseases and some degenerative diseases and depression in previous studies $(55,56)$. Further, the cardiovascular-degenerative disease pattern has been identified, and this pattern has the strongest association with poor HRQL and is the only pattern associated with poor HRQL in the mental health dimension(9). Some confirmed multimorbidity patterns and their overlap may indicate common underlying pathological mechanisms(52). In future research, these connections should be considered.

This is the first study of the association of multimorbidity patterns and depression among people covered by China's long-term care insurance. Our findings may be helpful for the improvement of China's long-term care insurance system and the optimization of service content. In addition, exploratory factor analysis was used to explore the multi-disease model and the oblimin rotation method was used; factors were allowed to be associated with each other, which is helpful in researching comorbidity between diseases $(29,57)$. Identifying specific disease patterns related to depression can help to improve understanding of the impact of multimorbidity on depression, not only focusing on the physical health of older people but also on mental health, which is equally important.

Our research also has some limitations. First, the cross-sectional nature of the study design does not allow causal inference of the observed associations. Thus, caution is needed when interpreting the findings. Second, some chronic diseases were ascertained based only on self-reported information, such that differential recall bias cannot be ruled out, with more severe diseases being more likely to be reported. Third, we did not consider the impact of disease severity; future research should incorporate more objective diagnoses and take disease severity into consideration.

\section{Conclusions}

In the present study, we found two of three different multimorbidity patterns to be associated with depression. Further, although certain physical conditions may not be associated with depression, they may have a strong correlation with depression after the formation of a specific disease pattern. Our study findings can help in exploring the possible interactions between different chronic diseases and to highlight mental health, which can improve approaches for managing chronic diseases as well as mental health in the older population. First, when assessing the nursing care level of older people with long-term care insurance, evaluation of their psychological status should be considered. Further, medical directors and physicians should pay greater attention to the mental health of the population with multimorbidity, to help prevent depression. Second, the psychological impact of patients' physical conditions should also be considered when treating depression. Finally, the impact of social support on physical and mental health should be emphasized in possible treatment.

\section{Acronyms}

CVD, cerebrovascular disease; AOR, adjusted odds ratio; Cl, Confidence Interval; HRQL, health-related quality of life; PSSS, Perceived Social Support Scale; GDS-30, the 30-item Geriatric Depression Scale; CNY: Chinese yuan; OR, odds ratio.

\section{Declarations}


Ethics approval and consent to participate: This study was approved by the ethical committee of School of Public Health Fudan University(IRB\# 2020-070840). The study was performed in accordance with the current institutional and state guidelines and regulations. Written informed consent was obtained from all participants. Informed consent of illiterate participants was obtained from legally authorized representative on their behalf.

Consent for publication: Not applicable.

Availability of data and materials: The datasets obtained and/or analyzed during the current study are available from the corresponding author on reasonable request.

\section{Competing interests: None.}

Funding: This work was supported by the National Natural Science Foundation of China (71974034) (http://www.nsfc.gov.cn). The funders had no role in the design of the study and collection, analysis, and interpretation of data and in writing the manuscript.

Authors' contributions: CCL: methods, data curation, and writing (original draft preparation). WJP: software and validation. MYL: investigation. XHL: investigation. TTY: investigation. HSY: methods and data curation. ZJW: methods, software and data curation. XJJ: supervision. ZH: supervision and writing (review and editing). YW: conceptualization and writing (review and editing).

Acknowledgements: We sincerely express our gratitude to all participants.

\section{References}

1. Kessler RC, Bromet EJ. The epidemiology of depression across cultures. Annu Rev Public Health. 2013;34:119-38.

2. GBD 2017 Disease and Injury Incidence and Prevalence Collaborators. Global, regional, and national incidence, prevalence, and years lived with disability for 354 diseases and injuries for 195 countries and territories, 1990-2017: a systematic analysis for the Global Burden of Disease Study 2017. Lancet. 2018;392(10159):1789-858.

3. Xu X, Mishra GD, Jones M. Evidence on multimorbidity from definition to intervention: An overview of systematic reviews. Ageing Res Rev. 2017;37:53-68. 4. Lutz W, Sanderson W, Scherbov S. The coming acceleration of global population ageing. Nature. 2008;451(7179):716-9.

5. Palladino R, Tayu Lee J, Ashworth M, Triassi M, Millett C. Associations between multimorbidity, healthcare utilisation and health status: evidence from 16 European countries. Age Ageing. 2016;45(3):431-5.

6. Britt HC, Harrison CM, Miller GC, Knox SA. Prevalence and patterns of multimorbidity in Australia. Med J Aust. 2008;189(2):72-7.

7. Pati S, Swain S, Hussain MA, van den Akker M, Metsemakers J, Knottnerus JA, et al. Prevalence and outcomes of multimorbidity in South Asia: a systematic review. BMJ Open. 2015;5(10):e007235.

8. Hu X, Huang J, Lv Y, Li G, Peng X. Status of prevalence study on multimorbidity of chronic disease in China: systematic review. Geriatr Gerontol Int. 2015;15(1):1-10.

9. She R, Yan Z, Jiang H, Vetrano DL, Lau JTF, Qiu C. Multimorbidity and Health-Related Quality of Life in Old Age: Role of Functional Dependence and Depressive Symptoms. J Am Med Dir Assoc. 2019;20(9):1143-9.

10. Riaño D, Peleg M, Ten Teije A. Ten years of knowledge representation for health care (2009-2018): Topics, trends, and challenges. Artif Intell Med. 2019;100:101713.

11. Roland M, Paddison C. Better management of patients with multimorbidity. Bmj. 2013;346:f2510.

12. Moussavi S, Chatterji S, Verdes E, Tandon A, Patel V, Ustun B. Depression, chronic diseases, and decrements in health: results from the World Health Surveys. Lancet. 2007;370(9590):851-8.

13. Read JR, Sharpe L, Modini M, Dear BF. Multimorbidity and depression: A systematic review and meta-analysis. J Affect Disord. 2017;221:36-46.

14. Anwar N, Kuppili PP, Balhara YPS. Depression and physical noncommunicable diseases: The need for an integrated approach. WHO South East Asia J Public Health. 2017;6(1):12-7.

15. Fang EF, Scheibye-Knudsen M, Jahn HJ, Li J, Ling L, Guo H, et al. A research agenda for aging in China in the 21st century. Ageing Res Rev. 2015;24(Pt B):197-205.

16. Zhang Y, Yu X. Evaluation of Long-Term Care Insurance Policy in Chinese Pilot Cities. Int J Environ Res Public Health. 2019;16(20).

17. Chang-Quan H, Bi-Rong D, Hong-Mei W, Yan-Ling Z, Jin-Hui W. Depression and medical illness in chinese nonagenarians and centenarians. J Am Geriatr Soc. 2008;56(12):2359-61.

18. Beard JR, Officer A, de Carvalho IA, Sadana R, Pot AM, Michel JP, et al. The World report on ageing and health: a policy framework for healthy ageing. Lancet. 2016;387(10033):2145-54.

19. Han KM, Ko YH, Yoon HK, Han C, Ham BJ, Kim YK. Relationship of depression, chronic disease, self-rated health, and gender with health care utilization among community-living elderly. J Affect Disord. 2018;241:402-10.

20. Zimet GD, Dahlem NW, Zimet SG, Farley GK. The Multidimensional Scale of Perceived Social Support. Journal of Personality Assessment. 1988;52(1):3041.

21. Chou K-L. Assessing Chinese adolescents' social support: the multidimensional scale of perceived social support. Personality and Individual Differences. 2000;28(2):299-307. 
22. Dai Y, Li X, Zhang X, Wang S, Sang J, Tian X, et al. Prevalence and Predisposing Factors for Depressive Status in Chinese Patients with Obstructive Sleep Apnoea: A Large-Sample Survey. PLoS One. 2016;11(3):e0149939.

23. Yesavage JA, Brink TL, Rose TL, Lum O, Huang V, Adey M, et al. Development and validation of a geriatric depression screening scale: a preliminary report. J Psychiatr Res. 1982;17(1):37-49.

24. Ganguli M, Hendrie HC. Screening for cognitive impairment and depression in ethnically diverse older populations. Alzheimer Dis Assoc Disord. 2005;19(4):275-8.

25. Jongenelis K, Pot AM, Eisses AM, Gerritsen DL, Derksen M, Beekman AT, et al. Diagnostic accuracy of the original 30-item and shortened versions of the Geriatric Depression Scale in nursing home patients. Int J Geriatr Psychiatry. 2005;20(11):1067-74.

26. Yunming L, Changsheng C, Haibo T, Wenjun C, Shanhong F, Yan M, et al. Prevalence and risk factors for depression in older people in Xi'an China: a community-based study. Int J Geriatr Psychiatry. 2012;27(1):31-9.

27. Chan AC. Clinical validation of the Geriatric Depression Scale (GDS): Chinese version. J Aging Health. 1996;8(2):238-53.

28. Prados-Torres A, Calderón-Larrañaga A, Hancco-Saavedra J, Poblador-Plou B, van den Akker M. Multimorbidity patterns: a systematic review. J Clin Epidemiol. 2014;67(3):254-66.

29. Ng SK, Tawiah R, Sawyer M, Scuffham P. Patterns of multimorbid health conditions: a systematic review of analytical methods and comparison analysis. Int J Epidemiol. 2018;47(5):1687-704.

30. Prados-Torres A, Poblador-Plou B, Calderón-Larrañaga A, Gimeno-Feliu LA, González-Rubio F, Poncel-Falcó A, et al. Multimorbidity patterns in primary care: interactions among chronic diseases using factor analysis. PLoS One. 2012;7(2):e32190.

31. Yao SS, Cao GY, Han L, Huang ZT, Chen ZS, Su HX, et al. Associations Between Somatic Multimorbidity Patterns and Depression in a Longitudinal Cohort of Middle-Aged and Older Chinese. J Am Med Dir Assoc. 2020.

32. You L, Yu Z, Zhang X, Wu M, Lin S, Zhu Y, et al. Association Between Multimorbidity and Depressive Symptom Among Community-Dwelling Elders in Eastern China. Clin Interv Aging. 2019;14:2273-80.

33. Alexopoulos GS. Depression in the elderly. Lancet. 2005;365(9475):1961-70.

34. Gao S, Jin Y, Unverzagt FW, Liang C, Hall KS, Ma F, et al. Correlates of depressive symptoms in rural elderly Chinese. Int J Geriatr Psychiatry. 2009;24(12):1358-66.

35. Lai D, Tong H, Zeng Q, Xu W. The factor structure of a Chinese Geriatric Depression Scale-SF: use with alone elderly Chinese in Shanghai, China. Int J Geriatr Psychiatry. 2010;25(5):503-10.

36. Pan A, Franco OH, Wang YF, Yu ZJ, Ye XW, Lin X. Prevalence and geographic disparity of depressive symptoms among middle-aged and elderly in China. J Affect Disord. 2008;105(1-3):167-75.

37. Valkanova V, Ebmeier KP, Allan CL. CRP, IL-6 and depression: a systematic review and meta-analysis of longitudinal studies. J Affect Disord. 2013;150(3):736-44.

38. Niles AN, Smirnova M, Lin J, O'Donovan A. Gender differences in longitudinal relationships between depression and anxiety symptoms and inflammation in the health and retirement study. Psychoneuroendocrinology. 2018;95:149-57.

39. Jia H, Uphold CR, Wu S, Reid K, Findley K, Duncan PW. Health-related quality of life among men with HIV infection: effects of social support, coping, and depression. AIDS Patient Care STDS. 2004;18(10):594-603.

40. Lin N, Ye X, Ensel WM. Social support and depressed mood: a structural analysis. J Health Soc Behav. 1999;40(4):344-59.

41. Blazer DG, 2nd, Hybels CF. Origins of depression in later life. Psychol Med. 2005;35(9):1241-52.

42. Theeke LA, Goins RT, Moore J, Campbell H. Loneliness, depression, social support, and quality of life in older chronically ill Appalachians. J Psychol. 2012;146(1-2):155-71.

43. Stubbs B, Vancampfort D, Veronese N, Kahl KG, Mitchell AJ, Lin PY, et al. Depression and physical health multimorbidity: primary data and country-wide meta-analysis of population data from 190593 people across 43 low- and middle-income countries. Psychol Med. 2017;47(12):2107-17.

44. Clarke DM, Currie KC. Depression, anxiety and their relationship with chronic diseases: a review of the epidemiology, risk and treatment evidence. Med $J$ Aust. 2009;190(S7):S54-60.

45. Goodwin GM. Depression and associated physical diseases and symptoms. Dialogues Clin Neurosci. 2006;8(2):259-65.

46. Wolff JL, Starfield B, Anderson G. Prevalence, expenditures, and complications of multiple chronic conditions in the elderly. Arch Intern Med. 2002;162(20):2269-76.

47. Lee Y, Choi K, Lee YK. Association of comorbidity with depressive symptoms in community-dwelling older persons. Gerontology. 2001;47(5):254-62.

48. Agustini B, Lotfaliany M, Woods RL, McNeil JJ, Nelson MR, Shah RC, et al. Patterns of Association between Depressive Symptoms and Chronic Medical Morbidities in Older Adults. J Am Geriatr Soc. 2020;68(8):1834-41.

49. Matcham F, Rayner L, Steer S, Hotopf M. The prevalence of depression in rheumatoid arthritis: a systematic review and meta-analysis. Rheumatology (Oxford). 2013;52(12):2136-48.

50. Busija L, Lim K, Szoeke C, Sanders KM, McCabe MP. Do replicable profiles of multimorbidity exist? Systematic review and synthesis. Eur J Epidemiol. 2019;34(11):1025-53.

51. loakeim-Skoufa I, Poblador-Plou B, Carmona-Pírez J, Díez-Manglano J, Navickas R, Gimeno-Feliu LA, et al. Multimorbidity Patterns in the General Population: Results from the EpiChron Cohort Study. Int J Environ Res Public Health. 2020;17(12). 
52. Kirchberger I, Meisinger C, Heier M, Zimmermann AK, Thorand B, Autenrieth CS, et al. Patterns of multimorbidity in the aged population. Results from the KORA-Age study. PLoS One. 2012;7(1):e30556.

53. Court H, McLean G, Guthrie B, Mercer SW, Smith DJ. Visual impairment is associated with physical and mental comorbidities in older adults: a crosssectional study. BMC Med. 2014;12:181.

54. Kochi M, Kohagura K, Shiohira Y, Iseki K, Ohya Y. Chronic kidney disease, inflammation, and cardiovascular disease risk in rheumatoid arthritis. J Cardiol. 2018;71(3):277-83.

55. Hare DL, Toukhsati SR, Johansson P, Jaarsma T. Depression and cardiovascular disease: a clinical review. Eur Heart J. 2014;35(21):1365-72.

56. Dickens C, McGowan L, Clark-Carter D, Creed F. Depression in rheumatoid arthritis: a systematic review of the literature with meta-analysis. Psychosom Med. 2002;64(1):52-60.

57. Schäfer I, von Leitner EC, Schön G, Koller D, Hansen H, Kolonko T, et al. Multimorbidity patterns in the elderly: a new approach of disease clustering identifies complex interrelations between chronic conditions. PLoS One. 2010;5(12):e15941. 